\title{
Efficacy of citric acid denture cleanser on the Candida albicans biofilm formed on poly(methyl methacrylate): effects on residual biofilm and recolonization process
}

Fernanda Faot ${ }^{1 *}$, Yuri Wanderley Cavalcanti ${ }^{2}$, Martinna de Mendonça e Bertolini ${ }^{2}$, Luciana de Rezende Pinto ${ }^{1}$, Wander José da Silva ${ }^{2}$ and Altair Antoninha Del Bel Cury ${ }^{2}$

\begin{abstract}
Background: It is well known that the use of denture cleansers can reduce Candida albicans biofilm accumulation; however, the efficacy of citric acid denture cleansers is uncertain. In addition, the long-term efficacy of this denture cleanser is not well established, and their effect on residual biofilms is unknown. This in vitro study evaluated the efficacy of citric acid denture cleanser treatment on C. albicans biofilm recolonization on poly(methyl methacrylate) (PMMA) surface.
\end{abstract}

Methods: C. albicans biofilms were developed for $72 \mathrm{~h}$ on PMMA resin specimens $(\mathrm{n}=168)$, which were randomly assigned to 1 of 3 cleansing treatments (CTs) overnight (8 h). CTs included purified water as a control (CTC) and two experimental groups that used either a 1:5 dilution of citric acid denture cleanser (CT5) or a 1:8 dilution of citric acid denture cleanser (CT8). Residual biofilms adhering to the specimens were collected and quantified at two time points: immediately after CTs (ICT) and after cleaning and residual biofilm recolonization (RT). Residual biofilms were analyzed by quantifying the viable cells (CFU/mL), and biofilm architecture was evaluated by confocal laser scanning microscopy (CLSM) and scanning electron microscopy (SEM). Denture cleanser treatments and evaluation periods were considered study factors. Data were analyzed using two-way ANOVA and Tukey's Honestly Significant Difference (HSD) test $(a=0.05)$.

Results: Immediately after treatments, citric acid denture cleansing solutions (CT5 and CT8) reduced the number of viable cells as compared with the control $(p<0.01)$. However, after $48 \mathrm{~h}$, both CT groups (CT5 and CT8) showed biofilm recolonization $(p<0.01)$. Residual biofilm recolonization was also detected by CLSM and SEM analysis, which revealed a higher biomass and average biofilm thickness for the CT8 group $(p<0.01)$.

Conclusion: Citric acid denture cleansers can reduce C. albicans biofilm accumulation and cell viability. However, this $C T$ did not prevent biofilm recolonization.

Keywords: Biofilm, Denture hygiene, Denture Cleansers, Candida albicans, Poly(methyl methacrylate)

\footnotetext{
* Correspondence: fernanda.faot@gmail.com

'Department of Prosthodontics, School of Dentistry, Federal University of

Pelotas, Pelotas, Rio Grande, do Sul 96015-560, Brazil

Full list of author information is available at the end of the article
} 


\section{Background}

Candida spp. is one of the main causative organisms of denture-induced stomatitis, which is primarily due to its ability to adhere and form biofilms on oral cavity tissues and denture surfaces, as well as due to its resistance to antifungal agents [1-4]. This biofilm grows extensively on acrylic resin denture material and its effective removal is a significant challenge by both chemical and mechanical methods [2-5].

Many chemical denture cleansers that contain enzymes, sodium hypochlorite, alkaline peroxide, and acid solutions are available for use with mechanical brushing to remove the residual biofilm attached to denture surfaces [5-8]. Denture cleansing solutions have antimicrobial properties, as demonstrated by many studies [7-12]; however, none of these methods seem to effectively remove the biofilm and prevent recolonization on the denture surface [6,7].

Another type of denture cleanser contains citric acid and is available as a concentrated solution, which can be used daily (1:5 dilution) or weekly (1:8 dilution) after proper dilution (as indicated by the manufacturer). This cleanser acts as a chemotherapeutic agent that can effectively disrupt biofilms through a sequestering mechanism with calcium ions [13]. This mechanism allows citric acid to break calcium bridges and subsequently disrupt the biofilm matrix, which may lead to anti-biofilm activity $[14,15]$.

Citric acid solutions were evaluated for their ability to decontaminate implant surfaces [16], demonstrating a reduction in the number of pathogenic species. Although citric acid solutions are also effective against Streptococcus mutans biofilms and biofilms derived from multiple species that develop on titanium surfaces [16], the effect of citric acid cleansers against Candida biofilms on denture surfaces has not yet been reported.

Although continuous use of citric acid cleansers for 3 months showed adverse effects with greater ion release from Co-Cr alloys [17,18], no harmful effects have been demonstrated with denture materials in general [19]. In contrast, other denture cleansers, mainly those containing sodium hypochlorite, could increase surface roughness, decrease hardness, and eventually change the color of acrylic resins and denture liners [19-21]. Therefore, citric acid cleansers might be suitable for removable dentures and orthodontic appliances and for removing biofilms and preventing their recolonization.

Therefore, considering the scarcity of studies examining the efficacy of citric acid cleansers for removing biofilms from denture materials, the present study evaluated the efficacy of citric acid cleansers on Candida albicans biofilm recolonization on poly(methyl methacrylate) (PMMA).

\section{Methods}

\section{Experimental design}

This in vitro study used a randomized, blinded design. C. albicans biofilms were developed for $72 \mathrm{~h}$ on PMMA resin specimens $(n=168)$ and then randomly assigned to 1 of 3 cleansing treatments (CTs): purified water, used as a control (CTC); 1:5 dilution of citric acid denture cleanser (CT5); or 1:8 dilution of citric acid denture cleanser (CT8). Residual biofilms adhering to specimens were collected and quantified at two different time points: immediately after cleaning treatments (ICT group) or $48 \mathrm{~h}$ after the cleaning, when residual biofilm recolonization (RT group) would occur. Residual biofilms were analyzed by determining the number of viable cells $(\mathrm{CFU} / \mathrm{mL})$. Biofilm architecture was evaluated by confocal laser scanning microscopy (CLSM) and scanning electron microscopy (SEM). The study factors were denture cleanser treatments and evaluation periods (ICT or RT). The response variables were the number of viable cells and the architecture of $C$. albicans residual biofilms. A scheme of the experimental design is illustrated in the Additional file 1.

\section{Resin specimens}

Disc-shaped specimens (10 mm diameter, $2 \mathrm{~mm}$ thickness, and $219.8 \mathrm{~mm}^{2}$ area) of microwave-polymerized PMMA (Onda Cryl; Artigos Odontológicos Clássico Ltd, São Paulo, Brazil) were fabricated according to the manufacturer's instructions. After polymerization, the discs were immersed in purified water at $37^{\circ} \mathrm{C}$ for $48 \mathrm{~h}$ for residual monomer release [22]. The PMMA specimens were then ground with a horizontal polisher (model APL-4; Arotec, São Paulo, Brazil) and using progressively finer aluminum oxide papers (320-, 400-, and 600-grit) to standardize surface roughness at $0.34 \pm 0.02 \mu \mathrm{m}$. Before developing the biofilm, the discs were ultrasonically cleaned (Thornton $\mathrm{T}$ 740; Thornton-Inpec Eletrônica Ltda, Vinhedo, Brazil) with $70 \%$ alcohol and sterilized ultra-purified water (20 min) to remove contaminants and artifacts from the surface [23]. The absence of contamination was confirmed by immersing a sample of the specimens in sterile culture media.

The specimens were randomly assigned to 1 of the 3 treatment groups, which were further divided within the evaluated time points: immediately after treatments (ICT) and $48 \mathrm{~h}$ after cleaning and residual biofilm recolonization (RT). The number of specimens in each group $(n=12)$ was determined with preliminary tests, which confirmed the sample size yielded an adequate power (80\%) for detecting statistically significant differences.

\section{Salivary pellicle formation on specimens}

Before developing the biofilm assays, clean PMMA specimens were coated with saliva to mimic the oral cavity environment. Human whole saliva was donated by a healthy 
volunteer, who provided written informed consent. The Research and Ethics Committee of Piracicaba Dental School, State University of Campinas, approved this study. The saliva sample was collected at the same time of day, for each experiment, and the collection volume was limited to $50 \mathrm{~mL}$ per collection period.

Human whole saliva was collected by masticatory stimulation with flexible film (Parafilm M; American Can Co, Neenah, WI). Saliva was clarified by centrifugation at $3,800 \mathrm{~g}$ for $10 \mathrm{~min}$ at $4^{\circ} \mathrm{C}$. The supernatant was collected and sterilized by filtration $(22 \mu \mathrm{m})$ for immediate use. For each disc, a salivary pellicle was formed on the surface after incubation for $30 \mathrm{~min}$, at $37^{\circ} \mathrm{C}$ and $75 \mathrm{rpm}$, in an orbital shaker.

\section{Inoculum and growth conditions}

A loopful of yeast culture of C. albicans (ATCC 90028) was reactivated and incubated for $24 \mathrm{~h}$ at $37^{\circ} \mathrm{C}$. Afterwards, cells were harvested, suspended in Yeast Nitrogen Base (YNB) broth (Becton Dickinson, Franklin Lakes, NJ) supplemented with $100 \mathrm{mM}$ glucose. Cell density was spectrophotometrically (Spectronic 20; Bausch \& Lomb, Rochester, NY) standardized to a 0.25 optical density at $520 \mathrm{\eta m}$, which corresponded to $1 \times 10^{6} \mathrm{CFU} / \mathrm{mL}$ inoculum [24].

\section{Biofilm assay}

PMMA saliva-coated discs were placed vertically in polystyrene 24-well culture plates. Subsequently, $2 \mathrm{~mL}$ of the standardized cell suspension $\left(1 \times 10^{6} \mathrm{CFU} / \mathrm{mL}\right.$ of $\mathrm{C}$. albicans in YNB supplemented with glucose $100 \mathrm{mM}$ ) was added to each well. Biofilm was developed at $37^{\circ} \mathrm{C}$, and under $75 \mathrm{rpm}$ in an orbital shaker, for $72 \mathrm{~h}$, to allow biofilm maturation. The medium was changed every $24 \mathrm{~h}$. Biofilm assays were performed in triplicate in 3 independent experiments.

\section{Treatment protocols}

After the biofilm growth for $72 \mathrm{~h}$, the specimens were randomly assigned to 1 of $3 \mathrm{CTs}$ overnight $(8 \mathrm{~h})$. Citric acid cleanser (CURADEN BDC 105, Curaprox, Swiss) was diluted in purified water, according to the manufacturer's instructions, in 1:5 or 1:8 solutions, which are recommended for weekly or daily use, respectively. Each specimen was placed in a sterile beaker containing $8 \mathrm{~mL}$ of the treatment solution.

Following cleanser treatments $(8 \mathrm{~h})$, specimens were removed and washed twice in $2 \mathrm{~mL}$ of sterilized phosphatebuffered saline (PBS) solution ( $\mathrm{pH} \mathrm{7.4).} \mathrm{The} \mathrm{residual} \mathrm{bio-}$ films adhering to the specimens were immediately collected (ICT) or allowed to grow under the same conditions for $48 \mathrm{~h}$ (RT group) [10].

\section{Viable cell quantification from residual biofilm}

Residual biofilms were disrupted and adhered microorganisms were removed from specimens by sonication (7 W for $30 \mathrm{~s}$ ). Sonicated solutions were serially diluted in PBS and plated $(20 \mu \mathrm{L})$ in triplicate on Sabouraud Dextrose agar. The plates were incubated at $37^{\circ} \mathrm{C}$ under aerobic conditions for $48 \mathrm{~h}$. CFU were counted using a stereomicroscope, and the results are expressed in colony-forming units per $\mathrm{mL}(\mathrm{CFU} / \mathrm{mL})$.

\section{Biofilm architecture analysis: SEM}

Specimens with attached biofilms were rinsed with sterile PBS and placed in 1\% osmium tetroxide for $1 \mathrm{~h}$. Specimens were subsequently washed in purified water, dehydrated in a series of ethanol washes (70\% for $10 \mathrm{~min}, 95 \%$ for $10 \mathrm{~min}$, and $100 \%$ for $20 \mathrm{~min}$ ) and air-dried in a desiccator before sputter coating with gold [24,25]. Next, specimens were mounted on aluminum stubs and coated with gold. The biofilm surface features were visualized with SEM (JSM 5600LV, JEOL, Tokyo, Japan) at 1,500× in a high-vacuum mode at $15 \mathrm{kV}$.

\section{Biofilm architecture analysis: CLSM}

Biofilms formed on PMMA surfaces were stained using the Live/Dead BacLight Viability kit, comprising SYTO-9 and propidium iodide (PI). Before the CLSM examinations, specimens were protected from light and incubated at $37^{\circ} \mathrm{C}$ for $20 \mathrm{~min}[24,25]$. Images of stained biofilms were captured using a CLSM system (LEICA - TCS SP5, Leica Microsystems, Wetzlar, Germany). A series of images were obtained at $1-\mu \mathrm{m}$ intervals in the $\mathrm{z}$ section for a three-dimensional view of the biofilm. At least, five representative optical fields were examined for each specimen.

COMSTAT software was used to analyze CLSM images. The architecture properties of biofilms analyzed by COMSTAT included the biovolume $\left(\mu \mathrm{m}^{3} / \mu \mathrm{m}^{2}\right)$, average thickness $(\mu \mathrm{m})$, and roughness coefficient.

\section{Statistical analysis}

Data were analyzed using statistical software (SAS v. 9.0; SAS Institute, Inc, Cary, NC) with a significance level fixed at $5 \%$. The assumptions of equality of variances and normal distribution of errors were evaluated for each variable. When normality was violated, the data were logarithmically transformed. Factors interfering in the response variables (C. albicans viable cells, $\mathrm{CFU} / \mathrm{mL}$ ), bio-volume $(\mu \mathrm{m} 3 / \mu \mathrm{m} 2)$, average thickness $(\mu \mathrm{m})$ and roughness coefficient) were analyzed with two-way ANOVA (type and evaluation period). Post-hoc comparisons were performed using Tukey's Honestly Significant Difference (HSD) test.

\section{Results}

The two-way ANOVA comparisons showed that both study factors "treatments" (CTC, CT5, and CT8) and 
"evaluation periods" (ICT and RT) affected the viable cell quantification $(\mathrm{p}<0.01)$; but no statistical interactions were detected. However, for biofilm architecture parameters (bio-volume, average thickness, and roughness), the two-way ANOVA comparisons showed a statistical significant interaction $(\mathrm{p}<0.001)$ between the factors under study.

The use of citric acid cleansers resulted in no viable cell counts immediately after treatments for both experimental groups (CT5 and CT8) ( $<<0.01)$, as showed on Table 1 . However, $48 \mathrm{~h}$ after treatments, C. albicans CFU counts were detected in the viable cell quantification, demonstrating that residual biofilms could recolonize the PMMA surface specimens. Although citric acid CTs were not effective within $48 \mathrm{~h}(\mathrm{p}<0.01)$, these cleaning solutions showed lower number of CFU counts when compared with the control group $(\mathrm{p}<0.01)$ at both evaluation time points.

Biofilm architecture analyses are presented in Table 2. Statistically significant differences were detected for evaluation periods $(\mathrm{p}<0.01)$ and for denture cleanser treatments $(p<0.05)$. Immediately after treatments (ICT), biofilms treated with CT5 were more affected than those treated with CT8 and the control groups, showing a lower bio-volume and average thickness than those for the other groups $(\mathrm{p}<0.05)$. In addition, the CT8 group showed a higher roughness coefficient, indicating the biofilm was less compacted $(\mathrm{p}<0.05)$. After the recolonization period (RT), biofilms treated with daily cleansing solution (CT8) showed an increase in bio-volume and in average thickness when compared with those for the 1:5 dilution (CT5) and control (water) treatments $(\mathrm{p}<0.05)$.

Although there were no statistical differences in the architecture of biofilms treated with water or CT5 ( $>$ >0.05), differences in biofilms visualized by SEM and CLSM were detected among groups (Figures 1 and 2). As the figures suggest, biofilms from the control and citric acid groups showed different metabolic levels after each CTs for both evaluation periods.

Table 1 C. albicans viable cell quantification (average \pm SD) according to different treatments and evaluation period

\begin{tabular}{lcc}
\hline \multirow{2}{*}{$\begin{array}{c}\text { Cleansing } \\
\text { treatment }\end{array}$} & \multicolumn{2}{c}{ Viable Cell Counts (10 $\mathbf{C F U} / \mathbf{m L})$} \\
\cline { 2 - 3 } & \multicolumn{2}{c}{ Evaluation periods } \\
\cline { 2 - 3 } & $\begin{array}{c}\text { Immediately after } \\
\text { treatments (ICT) }\end{array}$ & $\begin{array}{c}\text { Allowed to } \\
\text { recolonize (RT) }\end{array}$ \\
\hline $\mathrm{CTC}-\mathrm{H}_{2} \mathrm{O}$ & $1.01 \pm 8.59^{\mathrm{Aa}}$ & $11.1 \pm 12.30^{\mathrm{Ba}}$ \\
$\mathrm{CT} 5-1: 5$ & $\mathrm{O}^{\mathrm{Ab}}$ & $1.92 \pm 3.64^{\mathrm{Bb}}$ \\
$\mathrm{CT} 8-1: 8$ & $\mathrm{O}^{\mathrm{Ab}}$ & $3.63 \pm 4.12^{\mathrm{Bb}}$ \\
\hline
\end{tabular}

Different uppercase letters indicate statistically significant differences $(p<0.01)$ between the evaluation periods [Immediately treated (ICT) and allowed to recolonize (RT)]. Distinct lowercase letters indicate statistically significant differences $(p<0.01)$ among treatments (CTC, CT5, and CT8).
Figure 1 presents representative SEM images of biofilms treated with purified water, CT5, and CT8 at the ICT and RT evaluation periods. Regarding the control treatment (purified water), no substantial changes in biofilm structure were detected. Hyphae were observed immediately after citric acid treatments (Figure $1 \mathrm{~B}$ and $\mathrm{C}$ ). We observed a dramatic reduction in the number of cells for the CT8 group immediately after treatments (Figure $1 \mathrm{C}$ ). In addition, we observed a slight reduction in cell numbers for CT5 at both time points (Figure 1B and E), compared with the control. Biofilms were identified for all groups after the recolonization period (Figure 1D, E and F) and larger number of cells were observed for the CT8 group at RT (Figure 1F).

\section{Discussion}

In the present study, we evaluated the efficacy of citric acid denture cleanser for removing or killing the C. albicans biofilm formed on the surface of PMMA specimens. A long-term effect of other denture cleansing solutions was demonstrated in previous studies [7,9], which also included evaluation of the gold standard solution (sodium hypochlorite). In the present study, only purified water was used as the control. Considering that it is well known that sodium hypochlorite is effective against Candida biofilms, our study aimed to show differences, if any, between citric acid denture cleanser and the absence of chemical treatment. The present study showed that the citric acid treatment was more effective than the absence of treatment; however comparisons with a gold standard solution remain to be tested.

The citric acid denture cleanser used in the present study was a blend of ultra-purified water and citric acid in non-toxic, water soluble, low-viscosity chemical solution, which can break calcium-ion bridges that serve as chemical binding sites connecting the EPS polymeric chains [13]. Based on the literature, citric acid is the chemotherapeutic agent with the highest potential for removing biofilms from contaminated titanium surfaces in vitro, although it did not achieve complete removal $[14,16]$.

In the present study, we observed a biofilm recolonization phenomenon in both experimental groups when cleaned specimens were maintained for $48 \mathrm{~h}$ more in a culture medium supplemented with glucose. Therefore, we found that citric acid disrupted the biofilms but did not totally remove them. This finding leads to the supposition that this denture cleanser can be an effective complementary method for biofilm removal once it allows the debris to be more easily removed from the denture surface. Thus, it is expected that citric acid presents a more consistent effect on biofilm removal when associated with a mechanical method, such as brushing, to completely remove the mature biofilm from dentures $[14,16,26]$. 
Table 2 Bio-volume $\left(\mu^{3} / \mu \mathrm{m}^{2}\right.$ ), average thickness $(\mu \mathrm{m})$, and roughness coefficient (average \pm SD) of $C$. albicans biofilms according to different treatments and evaluation period

\begin{tabular}{|c|c|c|c|c|c|c|}
\hline \multirow{3}{*}{ Treatments } & \multirow{2}{*}{\multicolumn{2}{|c|}{$\begin{array}{c}\text { Bio-volume } \\
\text { Evaluation periods }\end{array}$}} & \multirow{2}{*}{\multicolumn{2}{|c|}{$\begin{array}{l}\text { Average thickness } \\
\text { Evaluation periods }\end{array}$}} & \multirow{2}{*}{\multicolumn{2}{|c|}{$\begin{array}{c}\text { Roughness coefficient } \\
\text { Evaluation periods }\end{array}$}} \\
\hline & & & & & & \\
\hline & ICT & RT & ICT & RT & ICT & RT \\
\hline CTC & $10.77 \pm 1.5^{\mathrm{Aa}}$ & $1.30 \pm 1.2^{\mathrm{Ba}}$ & $12.25 \pm 2.1^{\mathrm{Aa}}$ & $1.53 \pm 1.4^{\mathrm{Ba}}$ & $0.11 \pm 0.1^{\mathrm{Aa}}$ & $1.41 \pm 0.4^{\mathrm{Ba}}$ \\
\hline CT5 & $12.61 \pm 3.1^{\mathrm{Aa}}$ & $1.14 \pm 0.6^{\mathrm{Ba}}$ & $11.97 \pm 3.1^{\mathrm{Aa}}$ & $1.04 \pm 0.6^{\mathrm{Ba}}$ & $0.21 \pm 0.2^{\mathrm{Aa}}$ & $1.73 \pm 0.1^{\mathrm{Ba}}$ \\
\hline Ст8 & $3.87 \pm 2.8^{\mathrm{Ab}}$ & $9.71 \pm 2.7^{\mathrm{Bb}}$ & $4.88 \pm 3.7^{\mathrm{Ab}}$ & $11.69 \pm 3.3^{\mathrm{Bb}}$ & $1.17 \pm 0.3^{\mathrm{Ab}}$ & $0.30 \pm 0.2^{\mathrm{Bb}}$ \\
\hline
\end{tabular}

Different uppercase letters indicate statistically significant differences $(\mathrm{p}<0.01)$ between the evaluation periods within treatments [Immediately treated (ICT); and Allowed to recolonize (RT)]. Distinct lowercase letters indicate statistically significant differences $(p<0.05)$ among treatments $(C T C, C T 5$, and CT8) within periods of evaluation.

Although the number of viable cells was null immediately after treatments with either citric acid cleansers, it should be noted that the number of viable cells identified by CFU assay has low sensibility when a small number of cells are viable. In an attempt to explain these results, we used CLSM as an auxiliary method for CFU assay by analyzing the biofilms with their three-dimensional structures preserved, which also showed viability. Therefore, the presence of residual biofilm was confirmed by SEM and CLSM analysis, and it was possible to observe reminiscent viable cells and biofilm structures in ICT. These residual biofilms contributed to surface recolonization after $48 \mathrm{~h}$, as was observed in RT.

The present study evaluated the 1:5 and 1:8 dilutions of citric acid cleanser to simulate its weekly and daily use. These solutions probably did not completely affect the basal layers of the biofilms. This phenomenon may be due to the presence of an extracellular matrix, which protected the biofilm from the cleanser, and the reminiscent cells in metabolic quiescence, which accounted for the recolonization after $48 \mathrm{~h}[1,27]$. Therefore, a single exposition to citric acid denture cleanser is not able to remove Candida biofilms, or prevent their recolonization.

Comparing the results from viable cell quantification and biofilm architecture analysis, we found that treatments with 1:5 and 1:8 dilutions of the citric acid solutions might have a delayed effect on the biofilm cells. Although many viable cells were seen in the CLSM images, these were not detected by viable cell assessment. This can be explained by the phenomenon known as Post-Antifungal Effect (PAFE), in which substances stored inside vacuoles might kill the cells over time [4].

According to PAFE, citric acid uptake by Candida cells during the treatments contributed to the absence of CFUs in the viable cell assessment, as well as the reduction in cell

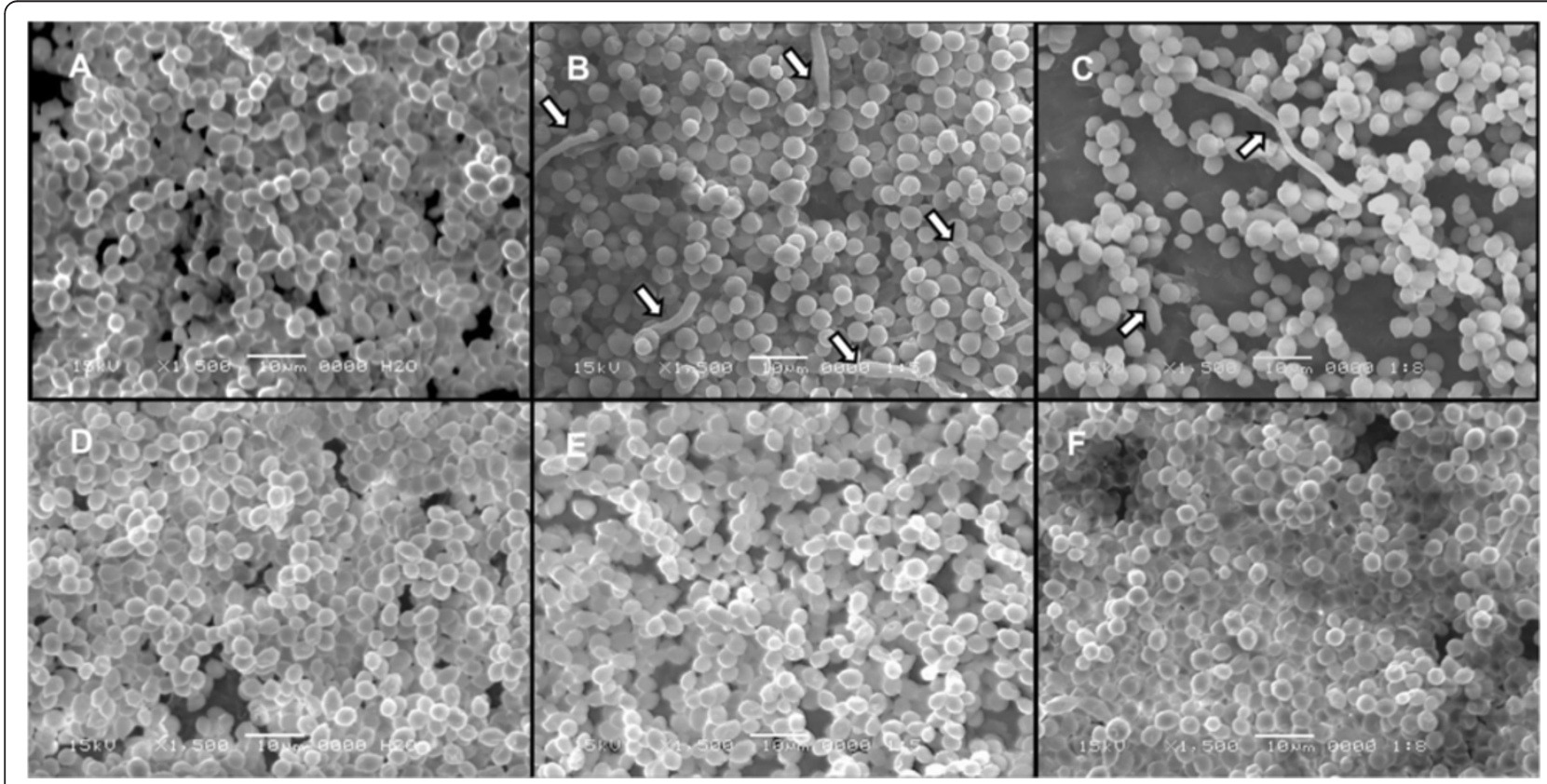

Figure 1 Representative scanning electron microscopy (SEM) images $(1,500 \times)$ of $C$. albicans biofilms according to different treatments and evaluation periods: A, CTC group (ICT); B, CT5 group (ICT); C, CT8 group (ICT); D, CTC group (RT); E, CT5 group (RT); F, CT8 group (RT). Note the hyphal (arrows) formation immediately after both citric acid solution treatments in ICT and the recolonization after $48 \mathrm{~h}$ (RT). 


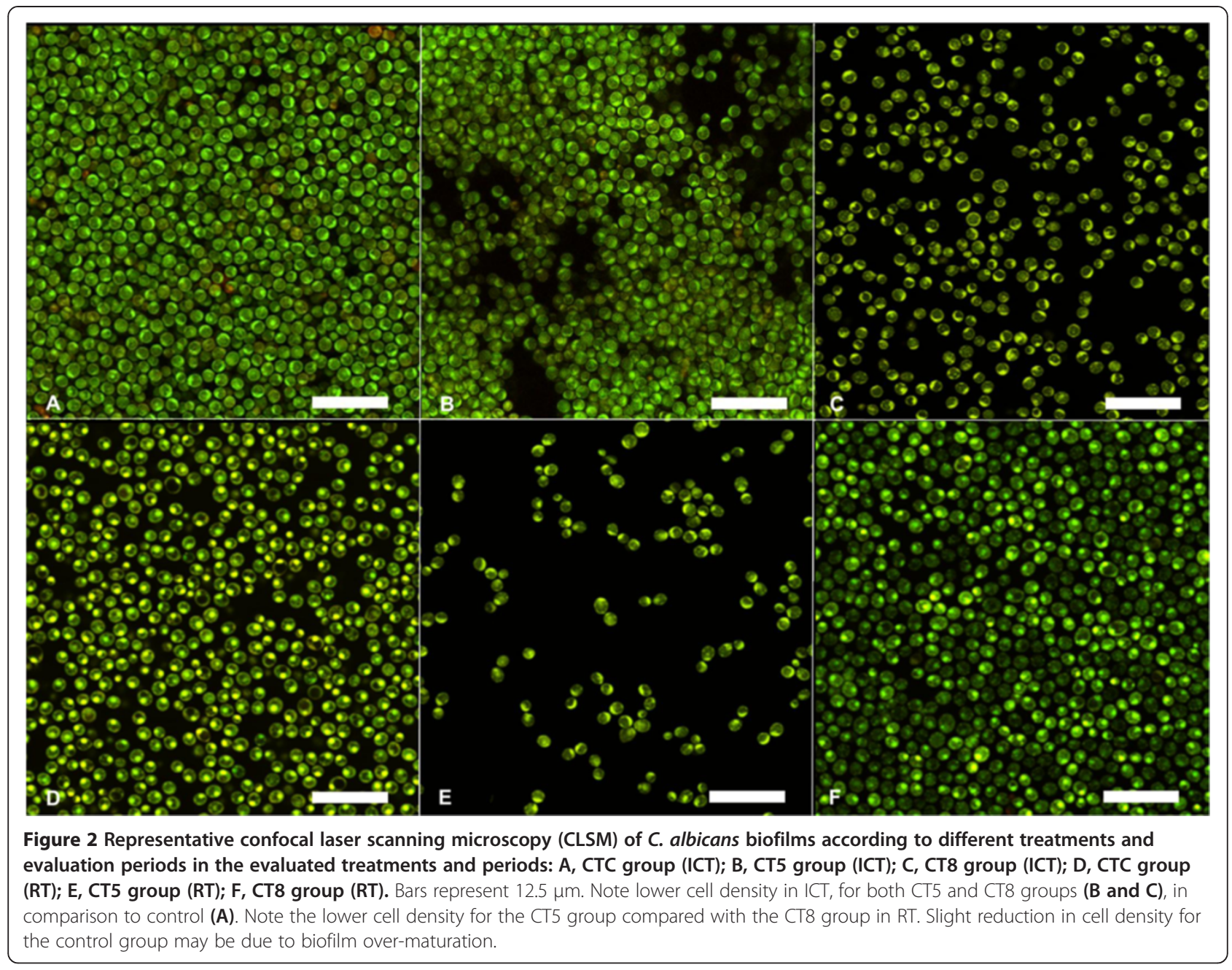

density for the 1:5 and 1:8 groups, as compared with the control. With regard to the biofilms visualized in RT, a higher biomass was observed for the CT8 group than for the CT5 group. This difference may be related to differences in the damage provoked by the two cleansers in RT, meaning that CT8 treatment allowed higher biofilm recolonization at the RT evaluation period.

According the PAFE and the results obtained with the CLSM images, biofilms treated in the 1:5 group showed greater damage than those in the 1:8 group. Basal layers from the biofilms treated with the 1:5 dilution seemed to show a greater response at ICT. This is because the 1.5 dilution treatment resulted in a lower biofilm bio-volume and average thickness at RT. Furthermore, the 1:8 dilution treatment did not deeply affect biofilms, allowing their extensively recolonization after $48 \mathrm{~h}$.

The results of the present study demonstrate that citric acid denture cleanser is effective in reducing $C$. albicans cell viability in a mature biofilm, immediately after treatments. However, this cleansing solution does not completely remove the biofilm and does not prevent its recolonization after $48 \mathrm{~h}$. Therefore, this study presents important findings regarding the anti-biofilm effect of citric acid denture cleanser.

The results of the present study should be interpreted with care because of the in vitro nature of the $72 \mathrm{~h}$ formed biofilm does not fully match the environment of the oral cavity. Also, during the initial 72 hours of initial biofilm formation, used to simulate a mature biofilm, there would be several microbial successions through time, which could be somewhat a limitation of the present study. However, the results provide important data on how the C. albicans biofilm behaves with daily and weekly treatments with citric acid denture cleanser used in clinical practice. Additional studies are needed with other Candida species in a single or mixed biofilm, which are increasingly implicated in long-term denture stomatitis. Also, these biofilms should be used for comparisons between the long-term efficacy of such treatments with citric acid and a gold standard solution (sodium hypochlorite), which would benefit the clinical treatment approaches. 


\section{Conclusion}

Within the limitations of this study, we found that citric acid denture cleansers reduced cell viability but did not prevent biofilm recolonization within $48 \mathrm{~h}$.

\section{Additional file}

Additional file 1: Scheme of the experimental design performed in the present study.

\section{Competing interests}

The authors declare that they have no competing interests.

\section{Authors' contributions}

FF, LRP, WJS, and AADBC conceptualized and designed the study. FF, LRP, and WJS collected the data. YWC and MMB interpreted and analyzed the data. FF, YWC, MMB, and LRP drafted the manuscript. WJS and AADBC performed the final review of the manuscript. All authors read and approved the final version of this manuscript.

\section{Acknowledgments}

The authors thank São Paulo State Research Supporting Foundation (Fundação de Amparo a Pesquisa do Estado de São Paulo) for the scholarships awarded to YWC and MMB (processes 12/07436-6 and 12/21011-8).

\section{Author details}

${ }^{1}$ Department of Prosthodontics, School of Dentistry, Federal University of Pelotas, Pelotas, Rio Grande, do Sul 96015-560, Brazil. ${ }^{2}$ Department of Prosthodontics and Periodontology, Piracicaba Dental School, State University of Campinas, Piracicaba, São Paulo 13414-903, Brazil.

\section{Received: 4 April 2014 Accepted: 20 June 2014}

Published: 23 June 2014

\section{References}

1. Gomes PN, da Silva WJ, Pousa CC, Narvaes EA, Del Bel Cury AA: Bioactivity and cellular structure of Candida albicans and Candida glabrata biofilms grown in the presence of fluconazole. Arch Oral Biol 2011, 56:1274-1281.

2. Salerno C, Pascale M, Contaldo M, Esposito V, Busciolano M, Milillo L, Guida A Petruzzi M, Serpico R: Candida-associated denture stomatitis. Med Oral Patol Oral Cir Bucal 2011, 16:e139-143.

3. Williams D, Lewis MAO: Pathogenesis and treatment of oral candidosis. Journal of Oral Microbiology. 2011, 3:5771-5782.

4. Ellepola AN, Samaranayake LP: Oral candidal infections and antimycotics. Crit Rev Oral Biol Med 2000, 11:172-198.

5. Paranhos HF, Silva-Lovato CH, Souza RF, Cruz PC, Freitas KM, Peracini A: Effects of mechanical and chemical methods on denture biofilm accumulation. J Oral Rehabil 2007, 34:606-612

6. de Souza RF: de Freitas Oliveira Paranhos H, Lovato da Silva CH, Abu-Naba'a L, Fedorowicz Z, Gurgan CA. Interventions for cleaning dentures in adults. Cochrane Database Syst Rev 2009, 7, CD007395

7. Vieira AP, Senna PM, Silva WJ, Del Bel Cury AA: Long-term efficacy of denture cleansers in preventing Candida spp. biofilm recolonization on liner surface. Braz Oral Res 2010, 24:342-348.

8. Dhamande MM, Pakhan AJ, Thombare RU, Ghodpage SL: Evaluation of efficacy of commercial denture cleansing agents to reduce the fungal biofilm activity from heat polymerized denture acrylic resin: An in vitro study. Contemp Clin Dent 2012, 3:168-172.

9. de Freitas Fernandes FS, Pereira-Cenci T, da Silva WJ, Filho AP, Straioto FG, Del Bel Cury AA: Efficacy of denture cleansers on Candida spp. biofilm formed on polyamide and polymethyl methacrylate resins. J Prosthet Dent 2011, 105:51-58.

10. da Silva PM, Acosta EJ, Pinto Lde R, Graeff M, Spolidorio DM, Almeida RS, Porto VC: Microscopical analysis of Candida albicans biofilms on heat-polymerised acrylic resin after chlorhexidine gluconate and sodium hypochlorite treatments. Mycoses 2011, 54:e712-717.

11. de Andrade IM, Cruz PC, da Silva CH, de Souza RF, Paranhos Hde F, Candido RC, Marin JM, de Souza-Gugelmin MC: Effervescent tablets and ultrasonic devices against Candida and mutans streptococci in denture biofilm. Gerodontology 2011, 28:264-270.

12. Sousa FA, Paradella TC, Koga-Ito CY, Jorge AO: Effect of sodium bicarbonate on Candida albicans adherence to thermally activated acrylic resin. Braz Oral Res 2009, 23:381-385.

13. Desrosiers M, Myntti M, James $G$ : Methods for removing bacterial biofilms: in vitro study using clinical chronic rhinosinusitis specimens. Am J Rhinol 2007, 21:527-532.

14. Ntrouka VI, Slot DE, Louropoulou A, Van der Weijden F: The effect of chemotherapeutic agents on contaminated titanium surfaces: a systematic review. Clin Oral Implants Res 2011, 22:681-690.

15. Valentine R, Jervis-Bardy J, Psaltis A, Tan LW, Wormald PJ: Efficacy of using a hydrodebrider and of citric acid/zwitterionic surfactant on a Staphylococcus aureus bacterial biofilm in the sheep model of rhinosinusitis. Am J Rhinol Allergy 2011, 25:323-326.

16. Ntrouka V, Hoogenkamp M, Zaura E, van der Weijden F: The effect of chemotherapeutic agents on titanium-adherent biofilms. Clin Oral Implants Res 2011, 22:1227-1234.

17. Felipucci DN, Davi LR, Paranhos HF, Bezzon OL, Silva RF, Pagnano VO: Effect of different cleansers on the surface of removable partial denture. Braz Dent J 2011, 22:392-397.

18. Davi LR, Felipucci DN, de Souza RF, Bezzon OL, Lovato-Silva CH, Pagnano VO, Paranhos HF: Effect of denture cleansers on metal ion release and surface roughness of denture base materials. Braz Dent J 2012, 23:387-393.

19. Durkan R, Ayaz EA, Bagis B, Gurbuz A, Ozturk N, Korkmaz FM: Comparative effects of denture cleansers on physical properties of polyamide and polymethyl methacrylate base polymers. Dent Mater J 2013, 32:367-375.

20. Polyzois G, Niarchou A, Ntala P, Pantopoulos A, Frangou M: The effect of immersion cleansers on gloss, colour and sorption of acetal denture base material. Gerodontology 2013, 30:150-156.

21. Senna PM, Vieira AP, Sotto-Maior BS, Silva WS, Del Bel Cury AA: Influence of immersion time of denture cleansers on the surface roughness of resilient denture liners. Rev Odonto Cienc 2011, 26:35-39.

22. Moura JS, da Silva WJ, Pereira T, Del Bel Cury AA, Rodrigues Garcia RC: Influence of acrylic resin polymerization methods and saliva on the adherence of four Candida species. J Prosthet Dent 2006, 96:205-211.

23. Senna PM, Da Silva WJ, Faot F, Del Bel Cury AA: Microwave disinfection: cumulative effect of different power levels on physical properties of denture base resins. J Prosthodont 2011, 20:606-612.

24. Seneviratne CJ, Silva WJ, Jin LJ, Samaranayake YH, Samaranayake LP: Architectural analysis, viability assessment and growth kinetics of Candida albicans and Candida glabrata biofilms. Arch Oral Biol 2009, 54:1052-1060.

25. da Silva WJ, Seneviratne J, Samaranayake LP, Del Bel Cury AA: Bioactivity and architecture of Candida albicans biofilms developed on poly(methyl methacrylate) resin surface. J Biomed Mater Res B Appl Biomater 2010, 94:149-156

26. Mouhyi J, Sennerby L, Pireaux JJ, Dourov N, Nammour S, Van Reck J: An XPS and SEM evaluation of six chemical and physical techniques for cleaning of contaminated titanium implants. Clin Oral Implants Res 1998, 9:185-194.

27. Nikawa $\mathrm{H}$, Hamada $\mathrm{T}$, Yamashiro $\mathrm{H}$, Kumagai $\mathrm{H}$ : A review of in vitro and in vivo methods to evaluate the efficacy of denture cleansers. Int $J$ prosthodont 1999, 12:153-159.

doi:10.1186/1472-6831-14-77

Cite this article as: Faot et al:: Efficacy of citric acid denture cleanser on the Candida albicans biofilm formed on poly(methyl methacrylate): effects on residual biofilm and recolonization process. BMC Oral Health 2014 14:77. 